Check for updates

Cite this: RSC Adv., 2018, 8, 20124

\title{
A lab-on-a-chip for preconcentration of bacteria and nucleic acid extraction
}

\author{
M. Hügle, (D) $\uparrow^{\mathrm{ab}}$ G. Dame, $\uparrow^{\mathrm{b}}$ O. Behrmann, ${ }^{\mathrm{ab}}$ R. Rietzel, ${ }^{\mathrm{a}}$ D. Karthe, (D) ${ }^{\mathrm{c}}$ F. T. Hufert ${ }^{\mathrm{b}}$ \\ and G. A. Urban ${ }^{a}$
}

To improve detection sensitivity, molecular diagnostics require preconcentration of low concentrated samples followed by rapid nucleic acid extraction. This is usually achieved by multiple centrifugation, lysis and purification steps, for instance, using chemical reagents, spin columns or magnetic beads. These require extensive infrastructure as well as time consuming manual handling steps and are thus not suitable for point of care testing (POCT). To overcome these challenges, we developed a microfluidic chip combining free-flow electrophoretic (FFE) preconcentration $(1 \mathrm{ml}$ down to $5 \mu \mathrm{l})$ and thermoelectric lysis of bacteria as well as purification of nucleic acids by gel-electrophoresis. The integration of these techniques in a single chip is unique and enables fast, easy and space-saving sample pretreatment without the need for laboratory facilities, making it ideal for the integration into small POCT devices. A preconcentration efficiency of nearly $100 \%$ and a lysis/gel-electrophoresis efficiency of about $65 \%$ were achieved for the detection of $E$. coli. The genetic material was analyzed by RT-qPCR targeting the superfolder Green Fluorescent Protein (sfGFP) transcripts to quantify mRNA recovery and qPCR to determine DNA background.

Received 12th March 2018

Accepted 22nd May 2018

DOI: $10.1039 / c 8 r a 02177 e$

rsc.li/rsc-advances overcome these problems, innovative systems are needed which are not only faster but also smaller and easier to handle and operate. Over the last two decades, considerable efforts have been undertaken to automate and integrate certain laboratory processes into miniaturized, chip-based devices. ${ }^{2}$ For preconcentration of bacteria from liquid samples, different approaches have been pursued. Currently used techniques include dielectrophoresis, ${ }^{3,4}$ antibody modified surfaces, ${ }^{\mathbf{5}, 6}$ acoustophoresis, ${ }^{7}$ micropillar sieving, ${ }^{8}$ the use of magnetic beads $^{\mathbf{9 , 1 0}}$ or electrophoretic transport. ${ }^{\mathbf{1 1}}$ For the extraction of nucleic acids, usually specific protocols or kits depending on the biological sample and medium are used. The use of magnetic beads, ${ }^{12,13}$ membrane based extraction ${ }^{2,14}$ or paperfluidics ${ }^{15}$ are some examples. In previous works, we have presented on-chip lysis and RNA extraction from bacteria ${ }^{\mathbf{1 6 , 1 7}}$ as well as FFE preconcentration of viable bacteria from liquid samples. ${ }^{18,19}$ Here, we present a lab-on-a-chip system based on these results. The chip includes on-chip FFE preconcentration and thermoelectric lysis of bacteria as well as separation of nucleic acids by on-chip gel-electrophoresis. The combination of these techniques in a single chip is unique and allows for fast, easy and space-saving sample pretreatment without the need for laboratory facilities, making it ideal for the integration into small POCT devices. Due to the exclusion of larger nucleic acid fractions (e.g. gDNA or plasmids) by on-chip gelelectrophoresis, the developed chip is especially suited for highly sensitive RNA based pathogen detection protocols. By simplifying the difficult and error prone extraction of pathogen- 
specific RNA, the chip enables transcriptome analysis at the point-of-care/need. As RNA transcripts are typically present in much higher copy numbers ${ }^{\mathbf{2 0} 21}$ than the singular copy of gDNA in each cell, targeting RNA can lead to powerful increases in detection sensitivity. This is especially important for the detection of clinically significant low-level infections such as bacteremia or infections of cerebrospinal fluid. ${ }^{22}$ To demonstrate the functionalities of the chip, fluorescent $E$. coli spiked into LB medium were concentrated from an initial volume of $1 \mathrm{ml}$ down to $5 \mu \mathrm{l}$. Preconcentration was directly followed by thermoelectric lysis of the bacteria and gel-electrophoresis of the released genetic material. The extracted nucleic acids were then analyzed by RT-qPCR to detect SfGFP $^{23}$ mRNA as a marker and qPCR to determine the residual DNA background.

\section{Materials and methods}

\section{Bacterial culture}

XL1-Blue competent $E$. coli transformed with a expression vector (pMH-33, $5.359 \mathrm{bp}$ ) containing the sfGFP gene were used for all experiments. Cells were grown in $5 \mathrm{ml}$ LB-Luria media with 100 $\mu \mathrm{g} \mathrm{ml}^{-1}$ ampicillin in a $15 \mathrm{ml}$ sterile plastic tube. After the prepared medium was inoculated with a single colony of the $E$. coli strain, the tube was placed in an incubator at $37{ }^{\circ} \mathrm{C}$ and shaken at $200 \mathrm{rpm}$. Eighteen hours later, the culture was diluted in $50 \mathrm{ml} \mathrm{LB}$-media with $100 \mu \mathrm{g} \mathrm{ml}^{-1}$ ampicillin in a sterilized $100 \mathrm{ml}$ culture flask. The culture was placed in the incubator at $37^{\circ} \mathrm{C}$ and shaken at $200 \mathrm{rpm}$. until the optical density at $600 \mathrm{~nm}$ (OD600) had increased from an initial value of 0.1 to a final value of 0.7. Arabinose was then added at a final concentration of $0.2 \%(\mathrm{w} / \mathrm{v})$ to induce sfGFP expression and the culture flask was incubated for an additional three hours. The bacteria were then immediately used for the experiments.

\section{Lab-on-a-chip}

The developed chip (Fig. 1) is made from Pyrex glass substrates and four layers of a dry-film photoresist (Ordyl SY300, Elga Europe). It combines free-flow electrophoretic preconcentration, thermoelectric lysis as well as on-chip gel-electrophoresis of nucleic acids.

\section{Layout}

The chip comprises four chambers separated by three $1 \mathrm{~mm}$ wide polyacrylamide gels. Control of wetted areas inside the chip is achieved by patterned hydrodynamic pressure barriers ("phaseguides"). ${ }^{24}$ The total dimensions of the chip are $16 \mathrm{~mm}$ $\times 1.12 \mathrm{~mm} \times 27 \mathrm{~mm}$ (width $\times$ height $\times$ depth). All chambers have a height of $120 \mu \mathrm{m}$ and a depth of $20 \mathrm{~mm}$. For preconcentration, lysis and electrophoresis two platinum electrodes at a distance of $10 \mathrm{~mm}$ are located in the outermost chambers. To reduce the risk of bubble trapping, these chambers have a width of only $1 \mathrm{~mm}$ resulting in a volume of $2.4 \mu \mathrm{l}$. The elution chamber is twice as wide $(4 \mathrm{~mm})$ as the sample chamber and has a volume of $10 \mu \mathrm{l}$.

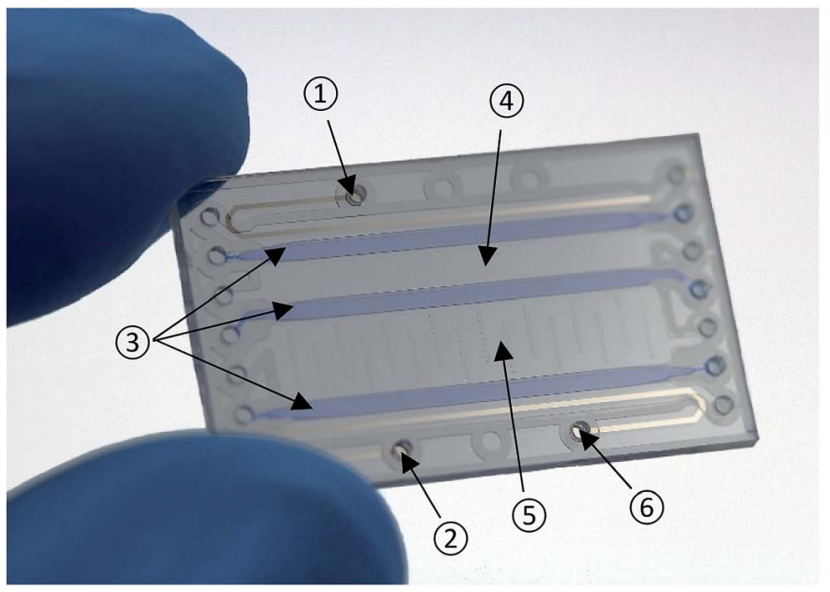

Fig. 1 Microfluidic chip for preconcentration and lysis of bacteria as well as gel-electrophoresis of nucleic acids. (1) Cathode (2) anode (3) hydrogel (4) sample chamber (sc) (5) elution chamber (ec) (6) electrode test pin (not used).

\section{Fabrication process}

Two 4 inch Pyrex glass wafers with a thickness of $500 \mu \mathrm{m}$ are used as the top and bottom substrates of the chip. In a first step, the electrodes consisting of two layers (50 $\mathrm{nm}$ titanium and $120 \mathrm{~nm}$ platinum) are patterned on the bottom wafer using a standard lift-off process. Then, four layers (30 $\mu \mathrm{m}$ each) of a dry-film photoresist are laminated onto it, followed by an exposure and development step that patterns the phaseguides and the chamber walls. After the inlet holes have been drilled into the top wafer, the wafers are thermally bonded and individual chips are released by dicing. Further details of the fabrication process may be found in Vulto et al. ${ }^{25}$

\section{Device operation}

The chip has three main functions that are performed consecutively. Prior to an experiment, a 5\% polyacrylamide gel $(125 \mu \mathrm{l}$ 40\% 29 : 1 acrylamide/bisacrylamide solution, $867.5 \mu \mathrm{l} 1 \times \mathrm{TBE}$, $2 \mu \mathrm{l} \mathrm{TEMED}$ and $5.5 \mu \mathrm{l} 10 \%$ ammonium persulfate) is dispensed into the provided chambers. After $15 \mathrm{~min}$ in a moisturized nitrogen atmosphere, the polymerization of the gel is complete and the chip is ready for use. Fig. 2 illustrates the general process flow:

(a) Free-flow electrophoretic preconcentration: the bacteria sample is pumped continuously through the sample chamber whilst a DC voltage $(100 \mathrm{~V})$ is applied between the cathode (black) and anode (red). Due to the perpendicular electrical field, the negatively charged bacteria are deflected towards the anode resulting in trapping at the middle gel barrier. To avoid bubble formation, the electrode chambers are rinsed with fresh $1 \times$ TBE at a flow rate of $200 \mu \mathrm{min}^{-1}$ during the complete process. Detailed information about the on-chip FFEpreconcentration can be found in the work of Podszun et al. ${ }^{19}$

(b) Lysis: a sinusoidal AC voltage $\left(20 \mathrm{kHz} / 230 \mathrm{~V}_{\mathrm{pp}}\right)$ is applied to cause lysis of the concentrated bacteria leading to a release of their genetic material. It is performed until the formation of heat induced gas bubbles is observed. Parameters for lysis are 

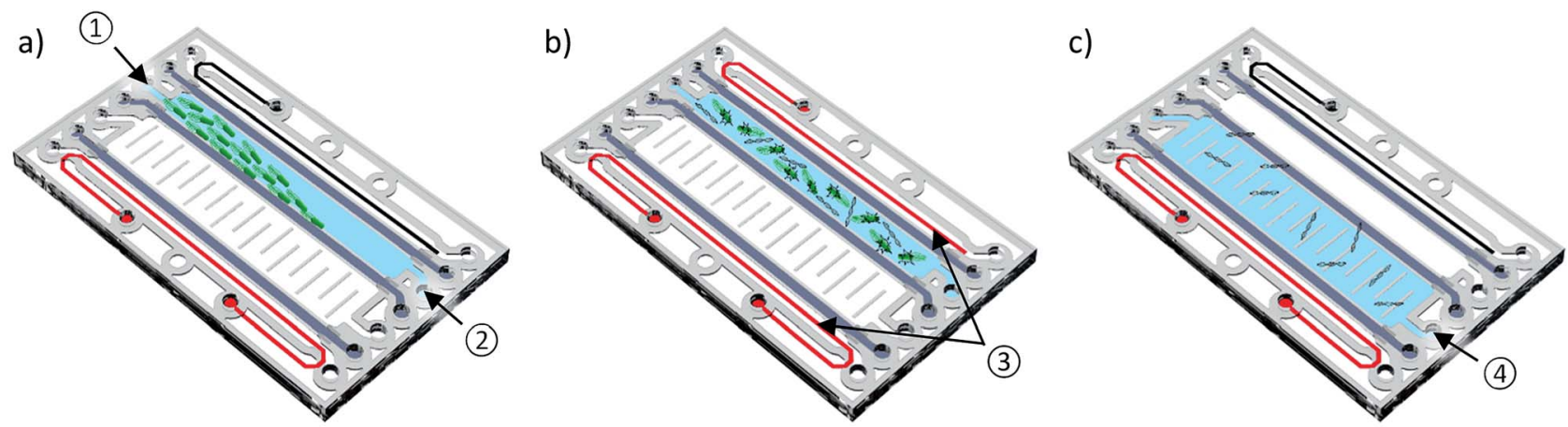

Fig. 2 CAD illustration of the process flow. (a) Bacteria are captured between the anode (red) and cathode (black) at the middle gel front using free-flow electrophoresis (1) inlet (sample) (2) outlet (waste), (b) a sinusoidal AC voltage is applied to cause lysis of the concentrated bacteria leading to a release of their genetic material (3) electrodes, (c) nucleic acids are transported through the middle gel into the elution chamber by gel-electrophoresis (anode: red, cathode: black). (4) Outlet (ec).

established by Vulto et al. $^{16}$ The devices used for lysis are a function generator (33120A, Hewlett-Packard) and a voltage amplifier (A600, FLC Electronics).

(c) Gel-electrophoresis: finally, the released nucleic acids are transferred through the middle gel into the elution chamber, which is filled with fresh $1 \times \mathrm{TBE}$, by gel-electrophoresis at a DC voltage of $100 \mathrm{~V}$. Larger cell debris is retained in the sample chamber.

All samples and extracts are immediately stored at $-20{ }^{\circ} \mathrm{C}$. Each experiment is repeated three times.

\section{Experimental setup}

Fig. 3 shows the custom chip holder milled from polyetheretherketone (PEEK). For preconcentration, a disposable poly methyl methacrylate (PMMA) connector is inserted into the chip holder. Two Luer- and four Lee (062 MINSTAC - The Lee Company) connectors as well as two spring probe pins are used for interfacing. Prior to an experiment, the sample is filled inside a $1 \mathrm{ml}$ syringe (B|BRAUN - Omnifix $\circledast \mathrm{F})$ and the chip is mounted into the fixture. By means of a syringe pump, the

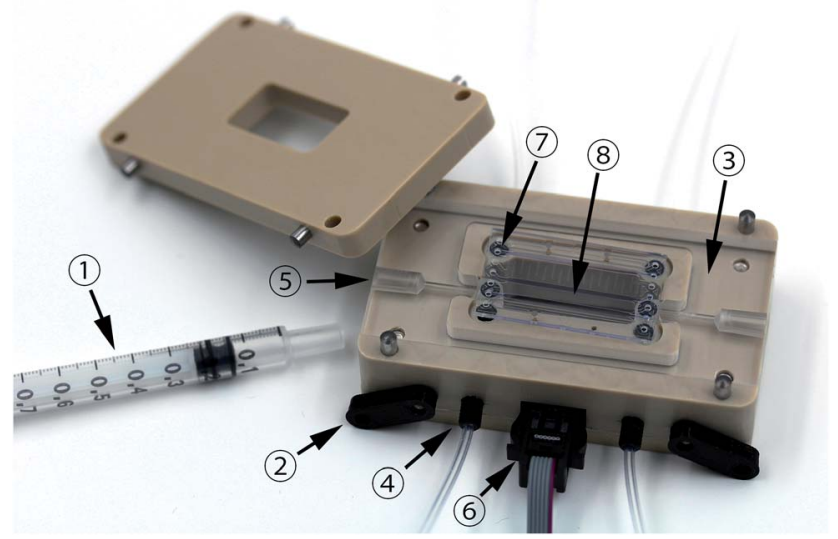

Fig. 3 CNC milled custom chip holder. (1) Syringe (2) pressure clamp (3) disposable PMMA connector (4) lee connector (5) luer connector (6) electrical port (7) O-ring (8) chip. sample is pumped through the chip into another $1 \mathrm{ml}$ syringe, which acts as waste reservoir.

\section{RT-qPCR and qPCR}

Eluted mRNA (758 bp) and plasmid DNA obtained from fluorescent $E$. coli were quantified using RT-qPCR and qPCR. Fluorescence readout and thermal cycling were performed using the LightCycler®1.5 (Roche). The supplied data analysis software suite was used to determine the cycle threshold $\left(C_{\mathrm{t}}\right)$. All error bars indicate standard deviation.

\section{Protocol for RT-qPCR}

Reverse transcription of the extracted mRNA and the qPCRreaction are carried out in one tube using Thermus thermophilus (Tth) polymerase (BIORON $\mathrm{GmbH}$ ). The total reaction volume of $20 \mu \mathrm{l}$ containing $5 \times$ RT-PCR buffer $(50 \mathrm{mM}$ bicine/ KOH, $115 \mathrm{mM}$ K-acetate, $40 \%$ glycerol $(\mathrm{v} / \mathrm{v}))$, dNTP mix $(0.2$ $\mathrm{mM}), \mathrm{MnCl}_{2}(4 \mathrm{mM})$, forward primer $\left(0.5 \mathrm{mM} / 5^{\prime}\right.$-CAAAGATGACGGGAC CTACA- $\left.3^{\prime}\right)$, reverse primer $\left(0.5 \mathrm{mM} / 5^{\prime}\right.$ CCAGTTTGTGTCCGA GAATG-3'), TaqMan probe $(0.3 \mathrm{mM} / \mathrm{FAM}$ TTCAAACTTGACT TCAGCACGCGTC-BBQ), Tth polymerase (2.5 $\mathrm{U} / \mathrm{rx}$ ) and $1 \mu \mathrm{l}$ sample is pipetted into LightCycler ${ }^{\circledR}$ capillaries. The size of the amplicon is $125 \mathrm{bp}$. The one step RT-qPCR cycle protocol begins with an initial denaturation for 2 min at $94{ }^{\circ} \mathrm{C}$ followed by reverse transcription $\left(30 \mathrm{~min}\right.$ at $\left.60^{\circ} \mathrm{C}\right)$ and 50 cycles of PCR $\left(15 \mathrm{~s}\right.$ at $94{ }^{\circ} \mathrm{C} ; 30 \mathrm{~s}$ at $\left.60{ }^{\circ} \mathrm{C}\right)$.

\section{Protocol for qPCR}

qPCR of the extracted plasmid DNA is carried out using Tth polymerase (BIORON $\mathrm{GmbH}$ ). The final reaction volume of the Tth polymerase mix amounts to $20 \mu \mathrm{l}$ and consists of $10 \times$ PCR buffer $\left(10 \mathrm{mM}\right.$ Tris-HCl, $100 \mathrm{mM} \mathrm{KCl}, 500 \mu \mathrm{g} \mathrm{ml}{ }^{-1} \mathrm{BSA}, 0.5 \%$ Tween 20 and $1.5 \mathrm{mM} \mathrm{MgCl}_{2}$ ), dNTP mix (0.2 mM), forward primer $(0.5 \mathrm{mM})$, reverse primer $(0.5 \mathrm{mM})$, TaqMan probe $(0.3$ $\mathrm{mM})$ and Tth polymerase $(2 \mathrm{U} / \mathrm{rx})$. After an initial denaturation step $\left(2\right.$ min at $\left.94{ }^{\circ} \mathrm{C}\right) 50$ cycles of PCR $\left(15 \mathrm{~s}\right.$ at $94{ }^{\circ} \mathrm{C}, 30 \mathrm{~s}$ at $\left.60^{\circ} \mathrm{C}\right)$ are performed. 
Table 1 Verification of sfGFP induction by arabinose. Lower $C_{\mathrm{t}}$-values indicate significant mRNA production with added arabinose ( $E$. coli (+ara.)) in comparison to samples without added arabinose during RTqPCR (E. coli (-ara.)). The plasmid DNA content measured by qPCR remains constant for both experimental conditions. $n=3$

\begin{tabular}{lll}
\hline & RT-qPCR & qPCR \\
\hline E. coli (+ara.) & $15.05 \pm 0.33$ & $20.16 \pm 0.49$ \\
E. coli (-ara.) & $19.09 \pm 0.83$ & $20.78 \pm 0.73$ \\
\hline
\end{tabular}

\section{Results and discussion}

To demonstrate the operation of the system, fluorescent $E$. coli were preconcentrated from an initial volume of $1 \mathrm{ml}$ down to 5 $\mu l$. Preconcentration was followed by thermoelectric lysis and on-chip gel-electrophoresis of released nucleic acids to remove larger fractions (e.g. gDNA or plasmids) and residual cell debris.

\section{Induction controls}

To verify the induction of sfGFP in the presence of arabinose, direct (RT)-qPCR of samples with and without added arabinose was performed omitting any preconcentration (Table 1).

The $C_{\mathrm{t}}$-values of the qPCR are constant for both experimental conditions, indicating a stable concentration of plasmid DNA. Interestingly, the RT-qPCR $C_{\mathrm{t}}$-value of the uninduced (E. coliara.) culture is in the same range (slightly higher $C_{\mathrm{t}}$-value) as the one obtained by qPCR, indicating that the RT-qPCR signal is predominantly due to the presence of the plasmid DNA background. The $C_{\mathrm{t}}$-values of the induced and uninduced samples show a difference of $4.04 \pm 0.51$, which corresponds to an about 16-fold increase in target copy number indicating successful sfGFP induction by arabinose. A $C_{\mathrm{t}}$-difference of $5.1 \pm 0.38$ was observed for $E$. coli (+ara.) when measured by RT-qPCR and qPCR, showing that sfGFP mRNA is present at about 34 -fold higher levels than the plasmid DNA after arabinose induction.

\section{Free-flow electrophoretic preconcentration of bacteria}

The deflection of the bacteria towards the anode and successful trapping at the middle gel barrier (Fig. 2, step a) highly depends on the strength of the applied electric field. Therefore, the voltage should be as high as possible to achieve a high preconcentration efficiency. However, the higher the voltage, the more heat induced gas bubbles were formed by resistive heating, interfering with the FFE inside the chip. Previous observations showed that a maximum DC voltage of $100 \mathrm{~V}$ could be applied to guarantee process stability. This means that electrolytic gas was removed efficiently from the electrode chambers and no formation of heat induced gas bubbles inside the chip was observed during the whole process duration. With a fixed voltage of $100 \mathrm{~V}$, the highest flow rate that achieved successful trapping of bacteria had to be determined. For this, a bacteria suspension was continuously pumped through the chip at different flow rates, whilst observing the chip under a fluorescence microscope. Fig. 4 shows the sample chamber of the chip at three different flow rates and a constant DC voltage of $100 \mathrm{~V}$.

\section{$10 \mu \mathrm{l} / \mathrm{min}$}

$20 \mu \mathrm{l} / \mathrm{min}$

\section{$30 \mu \mathrm{l} / \mathrm{min}$}

Fig. 4 Microscopic image of the sample chamber at three different flow rates and a constant $D C$ voltage of $100 \mathrm{~V}$. The inlet is on the right side. The bright green beams are fluorescent bacteria, which were previously collected at the gel front. The red line highlights the deflection of the bacteria caused by the applied electrical field. The white arrows indicates the flow direction.

The inlet is on the right side. The bright green lines are bacteria, which were previously collected at the gel front. The red line highlights the deflection of the bacteria caused by the applied electric field. At a flow rate of $10 \mu \mathrm{lmin}^{-1}$ and $20 \mu \mathrm{l} \mathrm{min} \mathrm{m}^{-1}$ hardly any loss of visible bacteria was observed. At $30 \mu \mathrm{lmin}^{-1}$ there was a substantial number of bacteria observed exiting the flow channel. Thus, a DC voltage of $100 \mathrm{~V}$ and a sample flow rate of $20 \mu \mathrm{l} \mathrm{min}{ }^{-1}$ were chosen for all further experiments. To determine the preconcentration efficiency, suspensions of $E$. coli sfGFP $(500 \mu \mathrm{l}$ and $1000 \mu \mathrm{l})$ were reduced to a volume of $5 \mu \mathrm{l}$ (sample chamber volume) inside the chip (Fig. 2, step a), resulting in a 100- or 200-fold reduction of the sample volume. After preconcentration, the outflow (waste) as well as the initial sample were analyzed by direct RT-qPCR for the presence of sfGFP mRNA as well as for the presence of viable bacteria by the plate count method. Preconcentration efficiencies were then calculated according eqn (1) and eqn (2) for the plate-count method and for RT-qPCR, respectively.

$$
\begin{gathered}
\mathrm{EF}_{\mathrm{CFU}}=100-\frac{\mathrm{CFU}_{\text {outflow }}}{\mathrm{CFU}_{\text {inflow }}} \times 100 \\
\mathrm{EF}_{C_{\mathrm{t}}}=100-\frac{100}{2^{C_{\mathrm{t}, \text { outflow }}-C_{\mathrm{t}, \text { inflow }}}}
\end{gathered}
$$

Table 2 shows the results for the plate-count method and Table 3 for RT-qPCR.

Table 2 Results of the preconcentration experiments. The inflow and outflow (waste) fractions are analyzed for the presence of viable bacteria by the plate-count method. The experiment was carried out at a flow-rate of $20 \mu \mathrm{min}^{-1}$ and a DC voltage of $100 \mathrm{~V} . n=3$

Plate Count

$\mathrm{CFU}_{\text {inflow }}\left(\mathrm{ml}^{-1}\right)$

Inflow sample vol. $(\mu \mathrm{l})$

$\mathrm{CFU}_{\text {outflow }}\left(\mathrm{ml}^{-1}\right)$

Reduction in

sample volume

$\mathrm{EF}_{\mathrm{CFU}}$

$$
\begin{aligned}
& 6.22 \times 10^{6} \pm 6.05 \times 10^{5} \\
& 500 \\
& 8.19 \times 10^{3} \pm 5.32 \times 10^{3} \\
& 100 \text {-fold } \\
& 99.86 \% \pm 0.093
\end{aligned}
$$


Table 3 Results of the preconcentration experiments. The inflow and outflow (waste) fractions are analyzed by RT-qPCR for the presence of sfGFP mRNA. The experiment was carried out in triplicate at a flowrate of $20 \mu \mathrm{min}^{-1}$ and a DC voltage of $100 \mathrm{~V} . n=3$

\section{RT-qPCR}

$C_{\text {t,inflow }}$

Inflow sample vol. $(\mu \mathrm{l})$

$C_{\text {t,outflow }}$

Reduction in

sample volume

$\mathrm{EF}_{C_{\mathrm{t}}}$

$22.97 \pm 1.24$
1000
None $(>50$ cycles $)$
200 -fold
$>99.99 \%$

Both analysis methods showed that more than $99 \%$ of all detectable bacteria were successfully captured inside the chip at a flow rate of $20 \mu \mathrm{min}^{-1}$ and a DC voltage of $100 \mathrm{~V}$.

\section{Lysis}

Bacteria were thermoelectrically lysed by applying a sinusoidal voltage to the coplanar electrodes (Fig. 2, step b). The applied voltage and frequency were the same as shown by Vulto et al. ${ }^{\mathbf{1 6}}$ to be effective for the lysis of $E$. coli $\left(230 \mathrm{~V}_{\mathrm{pp}} / 20 \mathrm{kHz}\right)$. Lysis duration was limited by the formation of heat induced gas bubbles inside the microfluidic chambers. A duration of $60 \mathrm{~s}$ was found to be the longest possible time before unacceptable levels of bubbles occurred that pushed fluid out of the filling ports.

\section{On-chip gel-electrophoresis and detection of nucleic acids}

The electrophoretic migration time depends on the size of the desired nucleic acid fraction, the applied voltage as well as the composition and width of the polyacrylamide gel inside the chip. In order to determine the migration time of the nucleic acids from the sample into the elution chamber, a time series was performed. For this, a DC voltage $(100 \mathrm{~V})$ was applied to the electrodes (Fig. 2, step c). Eluted nucleic acids $(10 \mu \mathrm{l})$ were removed from the elution chamber and replaced with fresh $1 \times$ TBE-buffer every 30 seconds up to a maximum of 240 seconds using a pipette. The extracts were then analyzed for the presence of sfGFP transcripts and its DNA coding region by RT-qPCR and qPCR. Fig. 5 shows the $C_{\mathrm{t}}$-values (left axis) of the extracts from the elution chamber (30 s - $240 \mathrm{~s}$ ) obtained by qPCR (gray, dashed) and RT-qPCR (blue, dashed). The green line depicts the difference $\left(\Delta C_{\mathrm{t}}\right.$, right axis) of the qPCR and RT-qPCR results. The amount of extracted DNA remained almost constant over the complete time series, whereas the amount of extracted mRNA decreased sharply after $60 \mathrm{~s}$. The difference of the detected mRNA and DNA levels (green line, right axis) also decreased sharply after the $60 \mathrm{~s}$ fraction. As the goal was the reliable detection of the target sequence (mRNA) with a low background (DNA), a duration of $60 \mathrm{~s}$ was used for gelelectrophoresis for all further experiments as mRNA was detected at an about 855-fold $\left(\Delta C_{\mathrm{t}}=9.74 \pm 0.2\right)$ higher level than DNA.

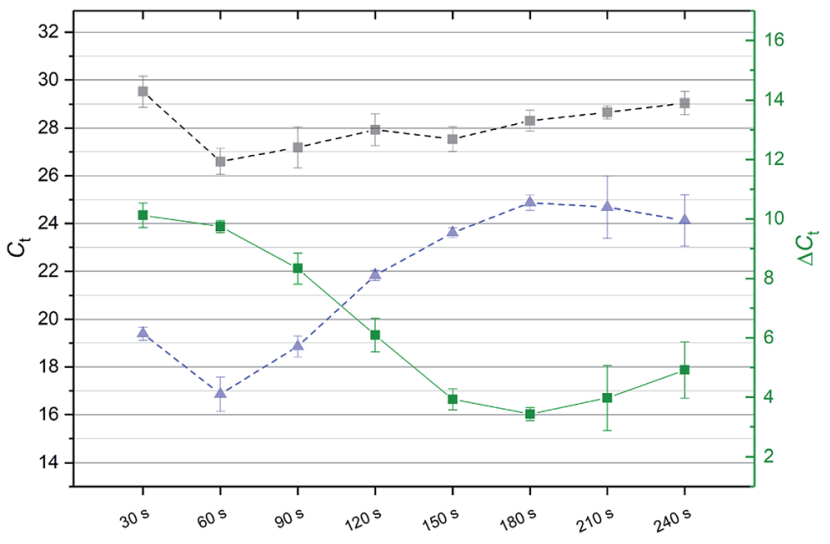

Fig. 5 Time series: $C_{t}$-values (left axis) of the extracts from the elution chamber (30 s - 240 s) obtained by qPCR (grey, dashed) and RT-qPCR (blue, dashed). The green line depicts the difference $\left(\Delta C_{t}\right.$, right axis) of the $\mathrm{qPCR}$ and RT-qPCR results. Error bars denote standard deviation. Each measuring point was carried out in triplicate $(n=3)$.

\section{Combined operation for signal enhancement}

To demonstrate the full functionality of the microfluidic chip, a bacteria suspension was diluted 200-fold and sfGFP mRNA was extracted by on-chip lysis and gel-electrophoresis with and without FFE preconcentration. First, mRNA was extracted from $5 \mu \mathrm{l}$ of the diluted bacteria suspension by on-chip lysis and gelelectrophoresis (Fig. 2, steps b and c). Next, $1000 \mu \mathrm{l}$ of the same diluted sample were preconcentrated by on-chip FFE within the sample chamber $(5 \mu \mathrm{l})$ and mRNA was extracted from the collected bacteria (Fig. 2, steps a, b and c). Table 4 shows the experimental results.

The mRNA extracted without preconcentration was detected at $C_{\mathrm{t}}=24.97 \pm 0.98$ and with preconcentration at $C_{\mathrm{t}}=17.88 \pm$ 1.65. The threshold-cycle difference of the two experiments $\left(\Delta C_{\mathrm{t}}\right.$ $=7.09$ ) corresponds to a 136- fold increase in mRNA concentration after preconcentration. The overall detection of bacteria is thus enhanced 136-fold by the addition of the FFE preconcentration step. Assuming a preconcentration efficiency of $>99 \%$, a 200 -fold increase in the amount of eluted mRNA is expected when comparing the mRNA amounts resulting from the experiments with and without FFE preconcentration. Considering the RT-qPCR results of the diluted $\left(C_{\mathrm{t}}=23.14 \pm\right.$ $0.87)$ and undiluted $\left(C_{\mathrm{t}}=15.44 \pm 0.95\right)$ sample material which were dispensed into the sample chamber, the expected amount of mRNA concentration increases up to 208-fold $\left(\Delta C_{\mathrm{t}}=7.70 \pm\right.$ $0.77)$. This allows for the calculation of the combined lysis/ electrophoresis efficiency of the chip system as

$$
\mathrm{EF}_{\mathrm{L} / \mathrm{E}}=\frac{2^{\Delta \mathrm{C}_{t}}}{D} \times 100
$$

Table 4 Combined operation for signal enhancement: $C_{t}$-values of the sfGFP mRNA extracted with and without preconcentration. $n=3$

$C_{\mathrm{t}}$, no preconcentration

$C_{\mathrm{t}}$, preconcentration
$24.97 \pm 0.98$

$17.88 \pm 1.65$ 
with $D$ being the dilution factor of the sample. With $\Delta C_{\mathrm{t}}=7.09$ and $D=208.14$ the combined lysis/electrophoresis efficiency equals $\mathrm{EF}_{\mathrm{L} / \mathrm{E}}=65.57 \%$ at the previously stated operating parameters for lysis and on-chip electrophoresis.

\section{Conclusions and outlook}

We have developed an lab-on-a-chip that combines highly efficient FFE preconcentration of bacteria with nucleic acid extraction for efficient detection of bacteria from dilute aqueous samples by organism specific mRNA. To demonstrate the full functionality of the chip, $1 \mathrm{ml}$ of a dilute bacteria sample was preconcentrated down to a volume of $5 \mu \mathrm{l}$. This step was followed by on-chip thermo-electric lysis and on-chip gelelectrophoresis of released mRNAs. All processing steps were completed in less than one hour with minimal hands-on time. Specific mRNA was then quantified in the extracts by RT-qPCR. The system showed an efficiency of nearly $100 \%$ for preconcentration and about $65 \%$ for on-chip lysis and gelelectrophoresis. Overall, a 136-fold signal improvement was achieved for the detection of bacteria by addition of the FFE preconcentration step. The unique combination of these techniques in a single chip allows for easy, fast and space-saving sample pretreatment making it ideal for the integration into small POCT devices. Furthermore, it reduces the risk of crosscontamination and the loss of sample material by additional pipetting steps.

To enable field deployment capability, we have developed a compact power supply using a boost converter for high-voltage generation and high-voltage operational amplifiers for amplification of the waveforms necessary for on-chip lysis. By optimizing the mRNA/DNA-separation, the developed chip system could be a very useful device for both gene expression studies and further RNA-based measurements such as RNAsequencing. For example, analysis of the bacterial transcriptome allows for more accurate determination of antimicrobial resistances at the point-of-care, as the sole presence of the resistance gene is often not directly related to the observed resistance phenotype(s). ${ }^{\mathbf{2 1 , 2 6}}$ Furthermore, the system may be suitable for the detection of viruses from dilute clinical samples such as those arising from e.g. bronchoalveolar lavage.

\section{Conflicts of interest}

There are no conflicts to declare.

\section{Acknowledgements}

The authors like to thank Dr Gregory Stevens for the protocol for sfGFP expression, Tobias Wieland for bacteria preparation, the German Federal Ministry of Education and Research (BMBF; Grant No. 033W010, EDIT) as well as the Ministry of Science, Research and Culture (MWFK; Grant No. 06-GeCa:H228-05/002/004, digilog-Gesundheitscampus Brandenburg) for funding this work. The pMH-33 plasmid was a generous gift from Prof. Dr Andreas Plückthun of the University of Zurich. The article processing charge was funded by the German Research Foundation (DFG) and the University of Freiburg in the funding programme Open Access Publishing.

\section{References}

1 D. Karthe, O. Behrmann, V. Blättel, D. Elsässer, C. Heese, M. Hügle, F. Hufert, A. Kunze, R. Niessner, J. Ho, B. Scharaw, M. Spoo, A. Tiehm, G. Urban, S. Vosseler, T. Westerhoff, G. Dame and M. Seidel, Environ. Earth Sci., 2016, 75, 1481.

2 L. van Heirstraeten, P. Spang, C. Schwind, K. S. Drese, M. Ritzi-Lehnert, B. Nieto, M. Camps, B. Landgraf, F. Guasch, A. H. Corbera, J. Samitier, H. Goossens, S. Malhotra-Kumar and T. Roeser, Lab Chip, 2014, 14, 1519-1526.

3 B. Del Moral-Zamora, J. Punter-Villagrassa, A. M. OlivaBranas, J. M. Alvarez-Azpeitia, J. Colomer-Farrarons, J. Samitier, A. Homs-Corbera and P. L. Miribel-Catala, Electrophoresis, 2015, 36, 1130-1141.

4 B. H. Lapizco-Encinas, R. V. Davalos, B. A. Simmons, E. B. Cummings and Y. Fintschenko, J. Microbiol. Methods, 2005, 62, 317-326.

5 K. Tsougeni, G. Papadakis, M. Gianneli, A. Grammoustianou, V. Constantoudis, B. Dupuy, P. S. Petrou, S. E. Kakabakos, A. Tserepi, E. Gizeli and E. Gogolides, Lab Chip, 2016, 16, 120-131.

6 U. Dharmasiri, M. A. Witek, A. A. Adams, J. K. Osiri, M. L. Hupert, T. S. Bianchi, D. L. Roelke and S. A. Soper, Anal. Chem., 2010, 82, 2844-2849.

7 P. Ohlsson, M. Evander, K. Petersson, L. Mellhammar, A. Lehmusvuori, U. Karhunen, M. Soikkeli, T. Seppa, E. Tuunainen, A. Spangar, P. von Lode, K. RantakokkoJalava, G. Otto, S. Scheding, T. Soukka, S. Wittfooth and T. Laurell, Anal. Chem., 2016, 88, 9403-9411.

8 K.-Y. Hwang, H.-K. Lim, S.-Y. Jung, K. Namkoong, J.-H. Kim, N. Huh, C. Ko and J.-C. Park, Anal. Chem., 2008, 80, 77867791.

9 A. J. Kell, G. Stewart, S. Ryan, R. Peytavi, M. Boissinot, A. Huletsky, M. G. Bergeron and B. Simard, ACS Nano, 2008, 2, 1777-1788.

10 N. Beyor, T. S. Seo, P. Liu and R. A. Mathies, Biomed. Microdevices, 2008, 10, 909-917.

11 A. K. Balasubramanian, K. A. Soni, A. Beskok and S. D. Pillai, Lab Chip, 2007, 7, 1315-1321.

12 P.-Y. Hung, P.-S. Jiang, E.-F. Lee, S.-K. Fan and Y.-W. Lu, Microsyst. Technol., 2015, 313-320.

13 Y. Sun, T. L. Quyen, T. Q. Hung, W. H. Chin, A. Wolff and D. D. Bang, Lab Chip, 2015, 15, 1898-1904.

14 E. A. Oblath, W. H. Henley, J. P. Alarie and J. M. Ramsey, Lab Chip, 2013, 13, 1325-1332.

15 N. M. Rodriguez, W. S. Wong, L. Liu, R. Dewar and C. M. Klapperich, Lab Chip, 2016, 16, 753-763.

16 P. Vulto, G. Dame, U. Maier, S. Makohliso, S. Podszun, P. Zahn and G. A. Urban, Lab Chip, 2010, 10, 610-616.

17 P. Vulto, P. Kuhn and G. A. Urban, Lab Chip, 2013, 13, 29312936. 
18 D. Puchberger-Enengl, S. Podszun, H. Heinz, C. Hermann, P. Vulto and G. A. Urban, Biomicrofluidics, 2011, 5, 441114411110.

19 S. Podszun, P. Vulto, H. Heinz, S. Hakenberg, C. Hermann, T. Hankemeier and G. A. Urban, Lab Chip, 2012, 12, 451-457. 20 B. Glynn, K. Lacey, J. Reilly, T. Barry, T. J. Smith and M. Maher, Res. J. Biol. Sci., 2007, 564-570.

21 C. Stein, O. Makarewicz, Y. Pfeifer, C. Brandt, J. C. Ramos, M. Klinger and M. W. Pletz, PLoS One, 2013, e80079.

22 S. A. Byron, K. R. van Keuren-Jensen, D. M. Engelthaler, J. D. Carpten and D. W. Craig, Nat. Rev. Genet., 2016, 17, 257-271.
23 J.-D. Pédelacq, S. Cabantous, T. Tran, T. C. Terwilliger and G. S. Waldo, Nat. Biotechnol., 2006, 24, 79-88.

24 P. Vulto, S. Podszun, P. Meyer, C. Hermann, A. Manz and G. A. Urban, Lab Chip, 2011, 11, 1596-1602.

25 P. Vulto, T. Huesgen, B. Albrecht and G. A. Urban, J. Micromech. Microeng., 2009, 19, 77001.

26 G. L. Daikos, P. Petrikkos, M. Psichogiou, C. Kosmidis, E. Vryonis, A. Skoutelis, K. Georgousi, L. S. Tzouvelekis, P. T. Tassios, C. Bamia and G. Petrikkos, Antimicrob. Agents Chemother., 2009, 53, 1868-1873. 